\title{
Mechanical Impedance Analysis of a Novel MEMS Photon Force Sensor ${ }^{+}$
}

\author{
Karolina Orłowska ${ }^{1, *}$, Wojciech Majstrzyk ${ }^{1}$, Andrzej Sierakowski ${ }^{2}$, Tomasz Piasecki ${ }^{1}$ and \\ Teodor Gotszalk ${ }^{1}$ \\ 1 Faculty of Microsystem Electronics and Photonics, Wroclaw University of Technology, 50-372 Wrocław, \\ Poland; Wojciech.Majstrzyk@pwr.edu.pl (W.M.); Tomasz.Piasecki@pwr.edu.pl (T.P.); \\ Teodor.Gotszalk@pwr.edu.pl (T.G.) \\ 2 Division of Silicon Microsystem and Nanostructure Technology, Institute of Electron Technology (ITE), \\ 02-668 Warsaw, Poland; ASierak@ite.waw.pl \\ * Correspondence: Karolina.Orlowska@pwr.edu.pl; Tel.: +48-71-320-2573 \\ + Presented at the Eurosensors 2018 Conference, Graz, Austria, 9-12 September 2018.
}

Published: 29 November 2018

\begin{abstract}
In this work we present how to describe mechanical impedance of a photon force (PF) MEMS sensor dedicated to structures' optomechanical studies. An actuating force (photon force) is caused by the reflection and absorption of the electromagnetic radiation beam due to the radiation pressure effect. Specially designed very soft (low k-constant, ca $10-150 \mathrm{mN} / \mathrm{m}$ ) cantilevers are presented. The structures integrate a Lorentz loop, which enables electromagnetic actuation. The construction with two mirrors is proposed so that parasitic thermal actuation can be neglected. The MEMS displacement is measured with the use of a laser vibrometer. The mechanical impedance model is presented using which the stiffness is calculated. As validation measurements: thermal noise and known mass adding methods are used.
\end{abstract}

Keywords: photon-force MEMS; mechanical impedance; dumped harmonic oscillator

\section{Introduction}

Microelectromechanical systems (MEMS) consist of integrated movable microstructures with electronics parts and their dimensions are as follows: cross-section in the order of single microns (1 $\mu \mathrm{m})$ and lengths in the order of 10-100 $\mu \mathrm{m}$. Analytical determination of MEMS mechanical parameters is often difficult, as the geometry and material composition of the today's structures is complex. Nevertheless, since they are commonly used as mechanical to electronic signal transducers (i.e., in much more complex devices and systems), their calibration is necessary.

There are many methods of the cantilevers' spring constant determination like Cleveland [1], Sader [2,3], Hutter and Bechhoffer [4], Butt and Jashke [5] or Holbery and Eden [6]. However, none of them is versatile for every type of beam's structure. For the MEMS cantilevers of complex shape, it is impossible to use any theoretical method and the investigations of very soft cantilevers $(\mathrm{k}<150$ $\mathrm{mN} / \mathrm{m}$ ) are even more challenging, as they exhibit low quality factor $\mathrm{Q}$ and the boundary conditions at the beam supporting point are becoming moreimportant.

Here we present the structures designed by our group and fabricated by the ITE in Warsaw (K. Orłowska, W. Majstrzyk, P. Kunicki, A. Sierakowski, B. Pruchnik, D. Tomaszewski, P. Prokaryn, P. Grabiec, T. Gotszalk, New design of the cantilevers for radiation pressure investigations, Microelectronic Engineering, under revision) They are made using silicon on insulator (SOI) technology. The material is highly doped (to be conductive, Boron Doped Silicon, BDS technique), so that the cantilever is stressed due to the crystal structure's modification. Since the force sensitivity depends on the 
cantilever's stiffness $\mathrm{k}$ and the quality factor $\mathrm{Q}$ it is necessary to describe precisely their values before the structure's application-here photon force reference actuation (Figure 1a).

As a method if investigations we present the mechanical impedance investigation method [7] for MEMS structures in ambient conditions analysis. The cantilever's array is used to increase the reliability of conducted research (Figure 1b).

\section{Materials and Methods}

To fully understand what and how the manufacturing steps affect the beams' behavior one must unravel what influences the $Q$ value. MetMolMEMS cantilever's quality factor is equal only to about 30. If the cantilever is modeled as a simple harmonic oscillator ( $\mathrm{SHO}$ ), it can be assumed that the beam is a weightless elastic spring with the stiffness $k$, at the end of which there is a suspended mass $m$ (here the effective mass of the cantilever), immersed in the viscous medium that causes the viscous dumping $b$. Then, the explanation is given in the damped harmonic oscillator Equation (1).

SHO equation resulting from Newton's second low is given as follows:

$$
m \frac{d^{2} x(t)}{\partial t^{2}}+b \frac{d x(t)}{\partial t}+k x(t)=0,
$$

and dividing by $\mathrm{m}$ :

$$
\frac{d^{2} x(t)}{\partial t^{2}}+\frac{b}{m} \frac{d x(t)}{\partial t}+\frac{k}{m} x(t)=0
$$

Then, giving the equation dependent on $\omega_{0}$ and while ${ }^{\omega_{0}=\sqrt{\frac{k}{m}}},\left(\omega_{0}\right.$ is undamped angular frequency of the oscillator):

$$
\frac{\mathrm{d}^{2} \mathrm{x}(\mathrm{t})}{\partial \mathrm{t}^{2}}+\frac{\omega_{0}}{\mathrm{Q}} \frac{\mathrm{dx}(\mathrm{t})}{\partial \mathrm{t}}+\omega_{0}^{2} \mathrm{x}(\mathrm{t})=0,
$$

So, the quality factor can be given by:

$$
Q=\frac{\sqrt{k m}}{b}
$$

To sum up, getting to know what is the reason why $Q$-factor is so small, one must determine the $k, m$ and $b$ separately. Mechanical impedance is then the best parameter that can help to resolve these values.

When the structure is excited by the force $F(t)$ Equation (3) can be rewritten as:

$$
\frac{d^{2} x(t)}{\partial t^{2}}+\frac{b}{m} \frac{d x(t)}{\partial t}+\frac{k}{m} x(t)=F(t)
$$

Mechanical impedance in this case is interpreted as the ratio between the excitation force $F(t)$ and the velocity of the structure movement $\frac{d^{2} x(t)}{\partial t^{2}}$. The parameters describing structure properties are in this case the mass of the structure $m$, its stiffness $k$ and the viscosity damping $b$.

Besides the standard damped harmonic oscillator, known mass added method [8] for $k$-constant calculations was used with the basic equation:

$$
k=\frac{(2 \pi)^{2} m}{\left(f_{m}^{2}-f_{0}^{2}\right)^{\prime}}
$$

where, $f_{0}, f_{m}$ are the resonance frequencies of the unloaded and loaded cantilever respectively and where the effective mass of the structure can be calculated as follows:

$$
m=\frac{f_{m}^{2} m_{s p h}}{f_{0}^{2}-f_{m}^{2}}
$$

$m_{\text {sph }}$ is known added mass value. Then viscous damping one can get from (4). 
In the thermomechanical noise method first stiffness $k$ is measured, then effective mass from (6) and viscous damping coefficient from (4) as above.

\section{Results}

Since the PF-MEMS cantilever are photon force driven structures, optical power fromSLED can be used to actuate them (Figure 1a). Every RP-cantilever is a U-shaped conductive structure and has two suspended mirrors: one for the actuation and one for the detection (Figure 1b). Both are covered with a thin gold film to ensure the beam reflectivity. Actuating mirror is also suspended on the cantilevers' legs for intentional thermal isolation from the rest of the structure (rounded-shaped in Figure $1 b$ ) to separate the mechanical (photon force) and thermal contribution to the movement. Due to the complex shape of investigated structures, no geometrical method can be used to estimate their parameters. So that two others: thermomechanical noise and known added methods were proposed.

To make the PF-MEMS cantilevers initial characterization thermomechanical noise method was used. All measured parameters: fres, $k$ and $Q$ are presented in Table 1.

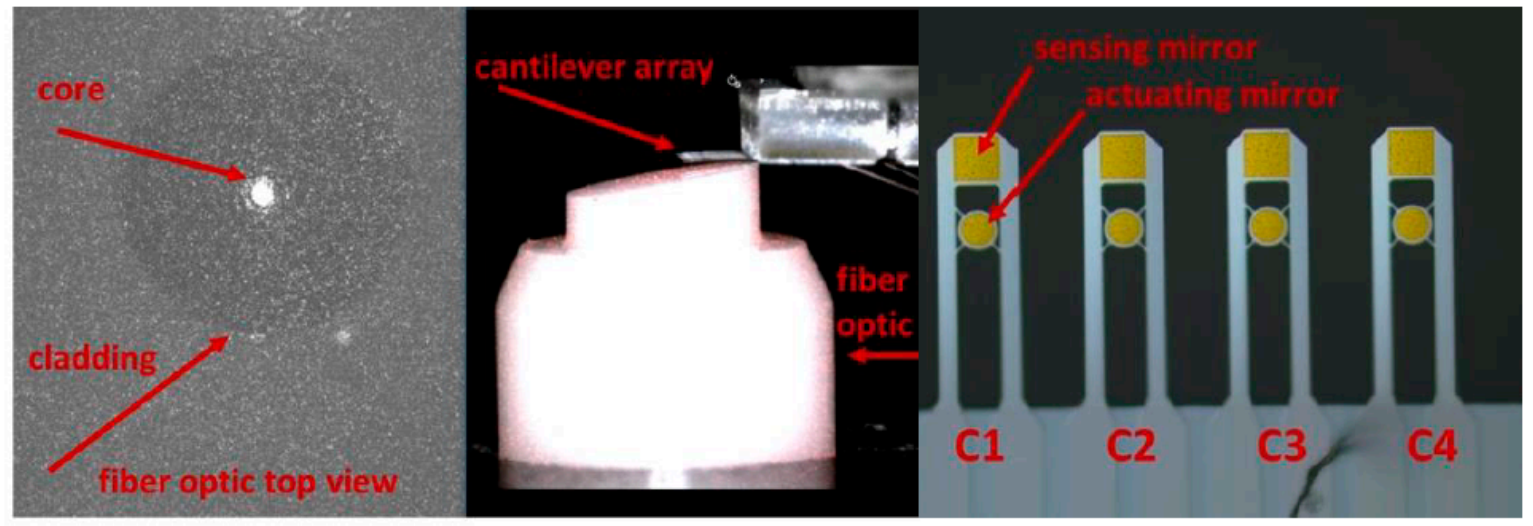

(a)

(b)

Figure 1. PF cantilever under the measurement process. (b) an PF cantilever array. Each cantilever is equipped with an actuating mirror (suspended) and sensing mirror at the very end.

Table 1. PF cantilever array parameters. These parameters were measured from vibrations caused by the intrinsic thermal noise.

\begin{tabular}{cccc}
\hline $\begin{array}{c}\text { Representative } \\
\text { Cantilever }\end{array}$ & $\begin{array}{c}\text { Spring Constant } \\
k[\mathrm{~N} / \mathrm{m}]\end{array}$ & $\begin{array}{c}\text { Quality Factor } \\
\boldsymbol{Q}\end{array}$ & $\begin{array}{c}\text { Resonant Frequency } \\
\text { fres }[\mathrm{kHz}]\end{array}$ \\
\hline $\mathrm{C} 1$ & 0.071 & 29.7 & 5.785 \\
\hline
\end{tabular}

For the mechanical impedance parameters measurement known mass adding method was used [8]. While putting the $\mathrm{SiO}_{2}$ microsphere covered with $50 \mathrm{~nm}$ gold layer (known mass-object, $m_{\text {sph }}=8$ $\mathrm{ng}$ ) onto the very end of the structure, the frequency shift was measured (where $f_{0}=5785, f_{1}=5468$ $\mathrm{Hz}$ ). So that taking into account $Q$ value the $k, m$ and $b$ parameters can be calculated. The results are presented in Table 2.

Table 2. PF cantilever mechanical impedance parameters.

\begin{tabular}{cccc}
\hline Method & $\begin{array}{c}\text { Spring Constant } \\
\boldsymbol{k}[\mathbf{N} / \mathbf{m}]\end{array}$ & $\begin{array}{c}\text { Effective Mass } \\
m[\mathbf{n g}]\end{array}$ & $\begin{array}{c}\text { Viscous Damping } \\
\boldsymbol{b}[\boldsymbol{\mu g} / \mathbf{s}]\end{array}$ \\
\hline known added mass s & 0.088 & 67 & 76.63 \\
thermal noise & 0.071 & 54 & 61.47 \\
\hline
\end{tabular}


Acknowledgments: The fabrication of the used structures was done within the NCN OPUS 9 Grant - “Metrology of molecular interactions using electromagnetically actuated MEMS force sensors-MetMolMEMS" (Grant No. 2015/17/B/ST7/03876). Methodology and metrology were financed by NCN Preludium Grant - "Mechanical impedance measurements of MEMS structures with the use of the photon force reference, PF-MEMS" (Grant No. 2017/25/N/ST7/02780).

Conflicts of Interest: The authors declare no conflict of interest

\section{References}

1. Cleveland, J.P.; Manne, S.; Bocek, D.; Hansma, P.K. A nondestructive method for determining the spring constant of cantilevers for scanning force microscopy. Rev. Sci. Instrum. 1993, 64, 403-405; doi:10.1063/1.1144209

2. Sader, J.E.; Larson, I.; Mulvaney, P.; White, L.R. Method for the calibration of atomic force microscope cantilevers. Rev. Sci. Instrum. 1995, 66, 3789-3798, doi:10.1063/1.1145439

3. Sader, J.E.; Chon, J.W.M.; Mulvaney, P. Calibration of rectangular atomic force microscope cantilevers. Rev. Sci. Instrum. 1999, 70, 3967-3969, doi:10.1063/1.1150021

4. Hutter, J.L.; Bechhoefer, J. Calibration of atomic-force microscope tips. Rev. Sci. Instrum. 1993, 64, 18681873; doi:10.1063/1.1143970

5. Butt, H.-J.; Jaschke, M. Calculation of thermal noise in atomic force microscopy. Nanotechnology 1995, 1-7, doi:10.1088/0957-4484/6/1/001

6. Holbery, J.D.; Eden, V.L.; Sarikaya, M.; Fisher, R.M. Experimental determination of scanning probe microscope cantilever spring constants utilizing a nanoindentation apparatus. Rev. Sci. Instrum. 2000, 71, 3769-3776, doi:10.1063/1.1289509

7. Wilkinson, P.R.; Shaw, G.A.; Pratt, J.R. Determination of a cantilever's mechanical impedance using photon momentum. Appl. Phys. Lett. 2013, 102, 2013-2016

8. Jóźwiak, G.; Kopiec, D.; Zawierucha, P.; Gotszalk, T.; Janus, P.; Grabiec, P.; Rangelow, I.W. The spring constant calibration of the piezoresistive cantilever based biosensor. Sens. Actuators B Chem. 2012, 170, 201206.

(C) 2018 by the authors. Licensee MDPI, Basel, Switzerland. This article is an open access article distributed under the terms and conditions of the Creative Commons Attribution (CC BY) license (http://creativecommons.org/licenses/by/4.0/). 